Miscelánea 



\title{
La filiación en el derecho internacional privado
}

\author{
Gonzalo García-Calderón Moreyra
}

\section{Filiación}

El derecho de familia regula la formación del núcleo fundamental de la sociedad, así como establece los derechos y obligaciones tanto de quienes forman dicho núcleo como de la relación entre ellos y la protección que el Estado les debe brindar.

El núcleo familiar ha ido variando con el devenir de la historia: el clan, la tribu, el matriarcado (la madre y sus hijos), el fraternal (lazo entre hermanos por encima del conyugal), el patriarcal (hombre con su o sus esposas e hijos) y el actual núcleo familiar con base en la igualdad del hombre y la mujer que con su consentimiento forman con sus hijos el núcleo familiar. Actualmente, dicho consentimiento se da mediante la forma legal expresa del matrimonio o mediante el reconocimiento legal por el transcurso del tiempo de la unión de hecho entre hombre y mujer.

La familia engendra relaciones jurídicas de gran trascendencia, tanto entre los integrantes de la pareja inicial, como con respecto a las personas que han derivado de ella. Y este es el aspecto que llevó a considerar a la familia como núcleo jurídico, en cuya organización interviene el Estado reglando todas las complejas consecuencias legales que este núcleo puede engendrar. (OMEBA, 1979, p. 992) 
Es así que la ley señala las características del matrimonio. Actualmente son: la igualdad de los cónyuges, la determinación del domicilio, la asistencia recíproca, la fidelidad, la patria potestad, el bienestar del menor; y de entre estas, muchas consecuencias que se derivan de esta unión. La filiación es una de las instituciones jurídicas que generan un tratamiento especial en el derecho de familia.

Respecto a esta institución, Héctor Cornejo Chávez manifiesta lo siguiente:

Pero de todas las relaciones, la más importante es sin duda la que se llama filiación, esto es, la que vincula a una persona con todos sus antepasados y sus descendientes (filiación en sentido genérico) $\mathrm{y}$, más restringidamente, la que vincula a los padres con sus hijos (filiación en sentido estricto). Desde este último punto de vista, que es el que particularmente nos interesa, la relación parental se denomina más propiamente paterno filial, pues si desde el ángulo del hijo se llama filiación, desde el punto de vista de los progenitores se denomina paternidad o maternidad. (1985, p. 357)

De igual modo, resulta pertinente tener en cuenta lo indicado por Varsi Rospigliosi, quien nos dice que:

Dentro de todas estas relaciones parentales la más importante y la de mayor jerarquía es la filiación (del latin: filus, hijo). Se entiende ésta como la relación jurídica parental existente entre el padre y su hijo. Consustancial del ser humano, la filiación forma parte del derecho a la identidad. De ahí han surgido nuevos derechos que tienden a la protección, como el derecho a la individualidad biológica y el derecho a conocer el propio origen biológico, prerrogativas, ambos, que son innatas en el hombre (ius eminis naturae). (2004, p. 87)

Existe una separación conceptual respecto a la institución denominada filiación, y son las llamadas filiación matrimonial y extramatrimonial; e históricamente existe un correlato legislativo y consuetudinario en que las consecuencias de haber nacido dentro o fuera del matrimonio generaban mayores derechos o ninguno frente a la sociedad y la ley.

La filiación es el vínculo natural entre padres e hijos sanguíneos o artificiales, como es el caso de la adopción. Para efectos de este artículo solo abordaré la filiación natural, es decir, el vínculo biológico de 
padres e hijos, el mismo que genera derechos y obligaciones, y no trataré la adopción.

Desde la Declaración Universal de los Derechos del Hombre de 1948, se reconoce que todos los niños, independientemente de su origen, tienen exactamente la misma protección legal, es por ello vital que se establezca la paternidad del niño. Esta protección comprende el derecho al apellido, alimentos, sucesión, entre otros.

En la medida en que todas las personas tienen una madre y un padre, tienen el derecho de conocer quiénes son estos, incluso en el caso de inseminación artificial $u$ otros de procreación asistida.

Los hijos extramatrimoniales, es decir, los concebidos y nacidos fuera del matrimonio, antiguamente llamados ilegítimos, tenían incluso categorías que hoy calificamos como abusivas y discriminatorias, como considerarlos hijos no naturales, adulterinos, incestuosos, sacrílegos, mánceres.

Nuestro Código Civil considera como parte de la filiación matrimonial a los hijos nacidos durante el matrimonio, y genera una presunción que si dentro de los 180 días de celebrado el matrimonio se produce el nacimiento, o si dentro de los 300 días siguientes a su disolución nace la criatura, se tiene por padre al marido.

El matrimonio, entendido como la unión voluntaria de hombre y mujer legalmente aptos, que se formaliza de acuerdo a las exigencias legales de cada país, genera en muchas legislaciones un principio de verosimilitud o presunción legal respecto al padre de la criatura, tan es así que por ejemplo nuestro Código Civil señala la prohibición de negar al hijo por nacer, en su artículo 366, en determinadas circunstancias ${ }^{1}$.

\section{Tratamiento en el derecho internacional privado}

El derecho internacional privado es una institución que tiene por objeto solucionar relaciones jurídicas vinculadas con más de un Estado u orde-

1 Artículo 366 del Código Civil.- Causales de improcedencia de la negación.

El marido no puede contestar la paternidad del hijo que alumbró su mujer en los casos del artículo 363, incisos 1 y 3:

1.- Si antes del matrimonio o de la reconciliación, respectivamente, ha tenido conocimiento del embarazo.

2.- Si ha admitido expresa o tácitamente que el hijo es suyo.

3.- Si el hijo ha muerto, a menos que subsista interés legítimo en esclarecer la relación paterno-filial. 
namiento jurídico, es decir, relaciones legales entre personas o entre personas y cosas. Es por ello que frente a conflictos generados entre personas o relaciones jurídicas vinculadas a legislaciones diferentes, surge la lógica duda de establecer quién será el juez competente que deberá resolver dicha controversia y cuál será la ley aplicable. Es por ello que se busca obtener reglas universales, aceptando el principio de que la elección del derecho aplicable se efectúe tomando en cuenta el derecho de las personas involucradas en la relación jurídica.

Es muy importante elegir un factor de conexión que permita que un juez y una ley determinada resuelvan el conflicto que se vincula a dos o más ordenamientos jurídicos. Manuel García-Calderón señala:

Si toda regla jurídica tiene como finalidad o como efecto, atribuir determinadas consecuencias jurídicas a las relaciones o a los hechos de los sujetos que en ellos intervienen a tomar parte, es propio que en las normas de Derecho Internacional Privado se atienda a las personas antes que a las relaciones o a los hechos, que son simplemente la manifestación o la consecuencia de la actividad lícita o ilícita de las personas. (Koechlin \& Calderón, 1969, p. 75)

Siendo que el derecho internacional privado se aplica a todas las relaciones jurídicas, sean de naturaleza civil, comercial, societaria, tributaria o procesal, es también aplicable al derecho de familia $\mathrm{y}$, por supuesto, a la filiación.

Es natural que dos personas tengan afinidad sentimental y que puedan ser de países diferentes, por lo que llegado el caso es necesario resolver el conflicto que se puede presentar respecto a los hijos generados de dicha unión, sea matrimonial o extramatrimonial, en el sentido de precisar cuál será la ley que regulará dicha relación.

En la legislación comparada de derecho internacional privado, la filiación se regula por el estatuto personal, es decir, o por la nacionalidad o el domicilio; sin embargo, es difícil precisar cuál debe ser el factor de conexión concreto a elegir, ya que puede referirse a la ley de nacionalidad o de domicilio del padre o del hijo, o puede remitirlo a la ley al momento de la concepción o al momento del nacimiento, a la residencia habitual del hijo, a la nacionalidad o domicilio de la madre.

El domicilio o la nacionalidad del padre dentro del matrimonio es la regla en algunas legislaciones; en otras, la filiación de un recién nacido, 
en relación con uno u otro de los padres, se determina por la ley del domicilio de ese padre en el momento del nacimiento. También, ya que la filiación puede ser considerada como un efecto del matrimonio, puede someterse a la ley común de los cónyuges, sea domicilio o nacionalidad, y el desplazamiento o cambio de domicilio no debe ser causa que perjudique el reconocimiento del hijo. Como vemos, el abanico de posibilidades es amplio, e incluso pueden darse fórmulas alternativas para favorecer la filiación.

En cuanto a los tratados multilaterales vinculados a este tema, ratificados y vigentes en el Perú, el Tratado de Montevideo de $1889^{2}$ señaló, en tres artículos, lo relativo a la filiación, indicando, en el artículo 16, que la ley que rige la celebración del matrimonio determina la filiación legítima y la legitimación por subsiguiente matrimonio; el artículo 17 señala que las cuestiones sobre legitimidad de la filiación, ajenas a la validez o a la nulidad del matrimonio, se rigen por la ley del domicilio conyugal en el momento del nacimiento del hijo, mientras que el artículo 18 señala que los derechos y obligaciones concernientes a la filiación ilegítima se rigen por la ley del Estado en el cual hayan de hacerse efectivos. La misma ley rige, según el Código de Bustamante de 192833, en su artículo 63, para la investigación de la paternidad y de la maternidad y su prohibición.

El Código de Bustamante eligió la ley personal en su artículo 57, indicando que son reglas de orden público interno, debiendo aplicarse la ley personal del hijo si fuera distinta a la del padre, las relativas a presunción de legitimidad y sus condiciones, las que confieren el derecho al apellido y las que determinan los pueblos de la filiación y regulan la sucesión del hijo. El doctor Delgado Barreto, por su parte, señala:

2 Tratado de Montevideo de 1889, sancionado por el Congreso Sudamericano de Derecho Internacional Privado, ratificado por Argentina, Bolivia, Paraguay, Perú y Uruguay. Se adoptaron tratados sobre derecho civil, comercial, procesal, penal, propiedad literaria y artística, marcas de fábrica, patentes de inversión y profesiones liberales. Colombia ratificó los tres primeros tratados.

3 Código de Bustamante o Código de Derecho Internacional Privado de 1928.- Fue adaptado por la Sexta Conferencia Internacional Americana, llevada a cabo en La Habana, Cuba. Ha sido ratificado por 15 países: Bolivia, Brasil, Costa Rica, Cuba, Chile, Ecuador, El Salvador, Guatemala, Haití, Honduras, Nicaragua, Panamá, Perú, República Dominicana y Venezuela. 


\begin{abstract}
Nosotros pensamos que hay que encontrar un equilibrio entre ambas posiciones extremas, dando al juez la facultad de poder escoger la conexión más adecuada que conduzca a la aplicación de la ley material más favorable al hijo, pero evitando caer en la utopía de pretender abarcar en las alternativas toda la heterogeneidad de las situaciones que la vida presenta en esta compleja materia. (Delgado B., Delgado M., \& Candela; 2002, p. 137)
\end{abstract}

Como se aprecia, la búsqueda de puntos de contacto o factores de conexión varían de legislación en legislación, e incluso en tratados de los cuales nuestro país es parte.

\title{
3. Libro $X$ del Código Civil peruano
}

Las normas de derecho internacional privado reguladas en el Código Civil peruano han establecido, a efectos de la filiación matrimonial, elegir la ley más favorable a la legitimidad (favor filli o favor filiationis), entre las de la celebración del matrimonio o la del domicilio conyugal al tiempo del nacimiento del hijo; mientras que, para el caso de la filiación extramatrimonial, así como sus efectos e impugnación, ha establecido la ley del domicilio común de ambos progenitores y del hijo, o, en su defecto, por la del domicilio del progenitor que tiene la posesión de estado respecto al hijo. Si ninguno de los progenitores tuviera la posesión de estado respecto al hijo, se aplicará la ley del domicilio del hijo.

\section{Filiación matrimonial}

Es claro que el legislador utiliza factores de conexión diferentes para la filiación matrimonial y la extramatrimonial, sin explicar la razón de ello, pero que pueden deducirse por las características diferentes de cada supuesto.

En cuanto a la filiación matrimonial, la doctora Revoredo refiere:

[...] respecto a la fijación temporal respecto al momento del nacimiento, que la comisión comprendió que el momento de la concepción es técnica y biológicamente más pertinente que el nacimiento, a fin de juzgar la legitimidad de la filiación, pero el inconveniente de su imprecisión temporal hace poco recomendable utilizarlo como identificador de la ley aplicable, por lo que la 
Comisión ha preferido al Código Civil portugués y a los proyectos venezolano y suizo, el hecho del nacimiento para fijar el domicilio conyugal vinculante, por tratarse de un lugar ostensible en un lugar y tiempo determinado. (1985, p. 989)

Es importante revisar este razonamiento de la Comisión Reformadora del Código Civil, puesto que el Libro I, dedicado al derecho de las personas, señala en su artículo I que la persona humana es sujeto de derecho desde su nacimiento, precisando que la vida humana comienza con la concepción, siendo sujeto de derecho en todo cuanto le favorezca.

Es decir que el legislador peruano es consciente de que puede haber un cambio de domicilio desde el momento de la concepción hasta el momento del nacimiento, pudiendo generarse un fraude a la ley o la aplicación de una ley menos beneficiosa, lo que sería contrario al espíritu de lo pensado por los legisladores. Sin embargo, es cierto también el razonamiento de la doctora Revoredo con relación a la imprecisión del lugar, es por ello que consideraron que era más adecuado fijar el lugar del domicilio conyugal al momento del nacimiento del hijo. Sin embargo, creo que incorporar también el lugar de la concepción como alternativa, abonaría y fortalecería el criterio del favor fillis.

Un ejemplo que puede ilustrar este tema es el siguiente: una pareja contrae matrimonio en un país árabe y luego viaja al Perú, donde fijan su domicilio y conciben a su hija, pero luego, por razones de trabajo, durante el embarazo son enviados de regreso al país árabe, donde se fija el domicilio conyugal y en donde se da a luz a una hija, de la cual, según las leyes de dicho país, el marido puede desconocer la paternidad o limitar ciertos derechos por ser mujer. Es evidente que la ley peruana sería más beneficiosa; sin embargo, dicho factor de conexión no ha sido considerado por nuestro legislador.

La doctora Luz Monge señala:

[...] obviamente, la ley más favorable al establecimiento de la legitimidad es competente para determinar el objeto y la carga de la prueba en materia de filiación matrimonial. Por ejemplo, la presunción relativa al momento de la concepción, la existencia y la fuerza de la presunción de la paternidad del marido (pater is est...) y lo relativo al ejercicio de la acción contestatoria. Corresponde a la misma ley, según lo relativo a los diferentes modos de prueba admisibles (posesión de estado, prueba sanguínea o gené- 
tica), a su fuerza probatoria, así como a los plazos y formalidades para interponer las acciones respectivas. (2006, p. 814)

El Código Civil peruano establece, en sus artículos 375 y 376, como prueba de la filiación matrimonial:

a) El título o instrumento que acredite la calidad matrimonial (partidas de nacimiento del hijo y de matrimonio de los padres, o por otro instrumento público).

b) El conjunto de medios que la ley procesal exige o admite dentro de juicio.

Es evidente, para mí, que será lógico utilizar como elemento probatorio la prueba genética de $\mathrm{ADN}$, establecida como elemento probatorio para la filiación extramatrimonial, en la discusión sobre impugnación de la filiación matrimonial. No serán aplicables las presunciones señaladas en la ley para la filiación no matrimonial.

El factor de conexión referido a la celebración del matrimonio está ligado también a un tema de aplicación de la ley, a efectos de discutir la validez o invalidez del matrimonio, que puede surgir como una cuestión previa a la discusión sobre la filiación.

En cuanto al domicilio conyugal, el Código Civil, en su Libro X, no regula dicho concepto, debiendo recurrirse al artículo 36 del mismo cuerpo legal, que señala que "el domicilio conyugal es aquel en el cual los cónyuges viven de consuno, o, en su defecto, el último que compartieron" (cursivas añadidas).

No olvidemos que el factor de conexión para la filiación matrimonial será el de celebración del matrimonio o el domicilio conyugal al momento del nacimiento del hijo, por lo que el domicilio conyugal puede ser el Perú, pero la madre puede dar a luz en los Estados Unidos de América, habiendo contraído matrimonio en Bolivia. En este supuesto, la ley aplicable será la peruana, en caso de que esta sea más favorable a la legitimidad que la ley de celebración, por ser el último domicilio de la pareja. Para finalizar, señalaré que en caso la ley peruana sea la aplicable, el juez peruano, en virtud del artículo 2062, podrá ser competente para conocer de dicha acción a pesar de que el domicilio del demandado no esté en nuestro país y coexistan tanto la norma peruana como la extranjera, siendo ambas favorables para la legitimidad del hijo. 
Artículo 2062.- Competencia en acciones personales

Los tribunales peruanos son competentes para conocer de los juicios originados por el ejercicio de acciones relativas al estado y la capacidad de las personas naturales, o a las relaciones familiares, aun contra personas domiciliadas en un país extranjero, en los casos siguientes:

1.- Cuando el derecho peruano es aplicable, de acuerdo con sus normas de derecho internacional privado, para regir el asunto.

2.- Cuando las partes se sometan, expresa o tácitamente, a su jurisdicción, siempre que la causa tenga una efectiva vinculación con el territorio de la República.

El problema de filiación se puede presentar en otras acciones ya no con carácter principal sino incidental o previo, como pueden ser casos de alimentos, sucesiones, etc. En tales casos, la competencia del juez no vendrá dada por la categoría filiación sino por aquella que constituya el objeto principal del juicio, y el problema de filiación se resolverá de acuerdo con las normas de cuestión previa del juez del foro. (Tovar Gil, 1987, p. 190)

\section{Filiación extramatrimonial}

En lo que respecta a la filiación extramatrimonial, nuestro Código señala que la determinación de este hecho, así como sus efectos y su impugnación, se regulan por la ley del domicilio común de ambos padres y del hijo, o en su defecto por la del domicilio del padre que tenga la posesión de estado respecto al hijo. Concluye indicando que en caso de que ninguno de los padres tuviera la posesión de estado, se aplicará la ley del domicilio del hijo.

Nuestros legisladores han optado por aplicar el factor de conexión al domicilio siguiendo la legislación norteamericana frente al criterio de la nacionalidad utilizado en algunos países europeos. Se trata de una opción legislativa, ya que hay una variedad de criterios, como hemos señalado en la introducción de este artículo: la nacionalidad o domicilio de la madre al momento del nacimiento del hijo, o el lugar del nacimiento del hijo, entre otros muchos. 
Tal como señalamos, el legislador busca favorecer el reconocimiento de la filiación extramatrimonial y establece un sistema de aplicación legislativa alternativa, basándose en el domicilio de los padres y del hijo en primer término, independientemente del lugar del nacimiento del hijo, siendo el criterio del domicilio el dominante y no el del nacimiento de la criatura. Luego establece un segundo criterio relacionado con el padre o la madre que tienen la posesión del hijo; y por último, la ley del domicilio del hijo, si este no se encontrara bajo la tenencia de ninguno de los padres. En este último supuesto, si el menor se encuentra, por ejemplo, con sus abuelos, será el domicilio del hijo, por intermedio del domicilio de su representante legal, ya que el domicilio del incapaz es el de sus representantes legales.

El fenómeno de las redes sociales permite que las relaciones personales de gente de distintas nacionalidades -incluso de países lejanostengan acceso virtual, que vía Internet se conozcan y se genere un vínculo emocional que termine en viajes para conocerse más y estrechar sus vínculos. Así, por ejemplo, una ciudadana peruana por la vía electrónica conoce a un australiano y este viaja al Perú, tienen relaciones sexuales y luego el hombre regresa a su país de origen con la promesa de que regresará para casarse; sin embargo ello no sucede, dejando a la chica embarazada.

Este supuesto es uno de los muchos que ocurren diariamente y en los que, existiendo elementos extranjeros en la relación jurídica, al tener domicilios diferentes, debemos recurrir al derecho internacional privado. En nuestro caso, el Libro $X$ establece que el domicilio de la madre y del hijo, al no existir domicilio común, permitirá la aplicación de la ley peruana, y siendo ello así el juez competente será también el juez peruano, en virtud del artículo 2062 ya mencionado.

El Perú ha establecido en su legislación interna, tanto para la paternidad como la maternidad, para el caso de los hijos nacidos fuera del matrimonio, el derecho de solicitar el reconocimiento judicial y así poder ejercer los derechos que se deriven de ello, independientemente del reconocimiento voluntario.

En efecto, el artículo 402 del Código Civil señala que para el caso de la paternidad extramatrimonial, esta puede ser jurídicamente declarada.

Artículo 402.- Procedencia de la Declaración Judicial de paternidad extramatrimonial 
La paternidad extramatrimonial puede ser judicialmente declarada:

1. Cuando exista escrito indubitado del padre que la admita.

2. Cuando el hijo se halle, o se hubiese hallado hasta un año antes de la demanda, en la posesión constante del estado de hijo extramatrimonial, comprobado por actos directos del padre o de su familia.

3. Cuando el presunto padre hubiera vivido en concubinato con la madre en la época de la concepción. Para este efecto se considera que hay concubinato cuando un varón y una mujer, sin estar casados entre sí, hacen vida de tales.

4. En los casos de violación, rapto o retención violenta de la mujer, cuando la época del delito coincida con la de la concepción.

5. En caso de seducción cumplida con promesa de matrimonio en época contemporánea con la concepción, siempre que la promesa conste de manera indubitable.

6. Cuando se acredite el vínculo parental entre el presunto padre y el hijo a través de la prueba del ADN u otras pruebas genéticas o científicas con igual o mayor grado de certeza. Ante la negativa de someterse a alguna de las pruebas, luego de haber sido debidamente notificado bajo apercibimiento por segunda vez, el juez evaluará tal negativa, las pruebas presentadas y la conducta procesal del demandado, declarando la paternidad o al hijo como alimentista, correspondiéndole los derechos contemplados en el artículo 415.

Lo dispuesto en el presente inciso no es aplicable respecto del hijo de la mujer casada cuyo marido no hubiese negado la paternidad.

El juez desestimará las presunciones de los incisos precedentes cuando se hubiera realizado una prueba genética $u$ otra de validez científica con igual o mayor grado de certeza.

Este último inciso fue incorporado mediante Ley 27048, y luego diversas leyes han regulado este procedimiento, siendo la Ley 29821 (publicada el 28 de diciembre de 2011, que modifica la Ley 28457) la que precisa el trámite de paternidad extramatrimonial, el cual señala que el demandado puede oponerse a la solicitud de paternidad en un plazo de diez días; de lo contrario su omisión a la contestación se convertirá en reconocimiento tácito, y en caso de que haya oposición a la paternidad 
está obligado a someterse a la prueba biológica de ADN y por el solo mérito de dicha prueba se resolverá la causa.

La norma señala que se tomarán muestras del supuesto padre, de la madre y del hijo. Es conveniente precisar que en los casos de fallecimiento del padre es posible solicitar al juez la exhumación del cadáver, a efectos de tomar muestras para practicar dicho análisis.

En nuestro ejemplo anterior, al padre de nacionalidad o domicilio australiano se le notificará vía exhorto, y deberá presentarse al juicio o de lo contrario se aplicará la presunción antes señalada. Una vez concluido el proceso, con la sentencia respectiva, la madre podrá iniciar el proceso de reconocimiento de sentencia (execuátur) en Australia y generar los efectos jurídicos que de la paternidad se deriven.

Un último escenario es aquel en que la madre da a luz al niño en el Perú y lo deja al cuidado de sus padres (los abuelos del niño recién nacido) y se va a Australia en busca del padre. En ese supuesto, los abuelos, que tienen la posición de estado respecto al niño, podrán acudir al juez peruano en virtud de que la ley aplicable es la del domicilio del hijo. Modificando un poco el ejemplo, si la madre peruana viaja a Ecuador, habiendo ocurrido la concepción en el Perú, pero arraiga domicilio en Ecuador, entendido como su residencia habitual según las leyes del país de residencia en donde se encuentran sus padres (abuelos de la criatura por nacer), y el niño nace en Ecuador, será allí el domicilio de la madre, por lo que no será la ley peruana la aplicable ni el juez peruano el competente.

\section{Conclusiones}

- Los factores de conexión para la filiación matrimonial son el lugar de celebración del matrimonio y el domicilio conyugal. Cualquiera de estas leyes alternativas se aplicará, en la medida en que favorezca el reconocimiento del menor.

- Considero que debe ampliarse como factor alternativo el lugar al momento de la concepción.

- Los factores de conexión para la filiación extramatrimonial son: el domicilio común de los padres y del hijo, el del padre que tiene la posesión de estado respecto al hijo, y si ninguno lo tuviera se aplicará el domicilio del hijo. En resumen, el factor de conexión será siempre el del domicilio del hijo. 
- Cuando se aplique el derecho peruano deberá aplicarse la Ley 29871, que incorpora la prueba genética de ADN.

\section{Referencias}

Basz, V., \& Campanella, E. (1999). Derecho internacional privado. Buenos Aires: Rubinzal Culzoni Editores.

Cornejo Chávez, H. (1985). Derecho familiar peruano (5 ${ }^{\mathrm{a}}$ ed., tomo II). Lima: Editorial Studium.

Delgado Barreto, C., Delgado Menéndez, M.A., \& Candela Sánchez, C. (2002 y 2007). Introducción al derecho internacional privado (tomo I y tomo II). Lima: Fondo Editorial de la Universidad Católica del Perú.

García-Calderón Koechlin, M. (1969). Derecho internacional privado. Lima: Fondo Editorial de la Universidad Nacional Mayor de San Marcos.

Monge Talavera, L. (2006). Código Civil comentado (tomo X, p. 814). Lima: Gaceta Jurídica.

OMEBA. (1979). Enciclopedia jurídica.

Revoredo, D. (1985). Exposición de motivos del Código Civil (tomo VI). Lima: Editorial Artes Gráficas de la Industria Avanzada.

Tovar Gil, M.C., \& Tovar Gil, J. (1987). Derecho internacional privado. Lima: Fundación Bustamante de la Fuente.

Varsi Rospigliosi, E. (2004). Divorcio, filiación y patria potestad. Lima: Editorial Grijley. 
